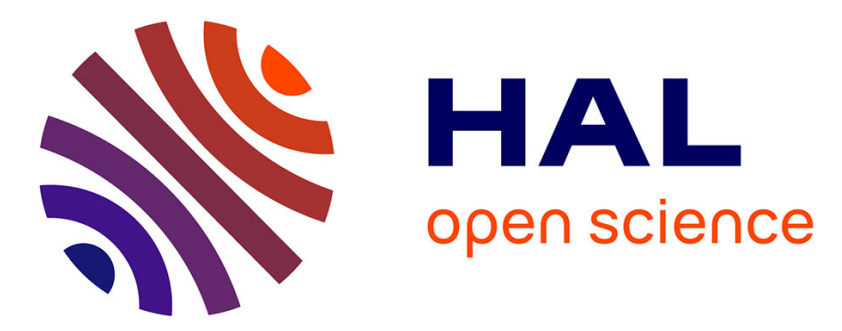

\title{
The impact of the particle size distribution of organic additives on the microstructure of a clay ceramic and its thermal and mechanical properties
}

Pierre-Marie Nigay, Ange Nzihou, Thierry Cutard

\section{- To cite this version:}

Pierre-Marie Nigay, Ange Nzihou, Thierry Cutard. The impact of the particle size distribution of organic additives on the microstructure of a clay ceramic and its thermal and mechanical properties. Journal of Materials in Civil Engineering, 2018, 30 (4), pp.04018044. 10.1061/\%28ASCE\%29MT.1943-5533.0002221 . hal-01701896

\section{HAL Id: hal-01701896 \\ https://hal.science/hal-01701896}

Submitted on 28 Feb 2019

HAL is a multi-disciplinary open access archive for the deposit and dissemination of scientific research documents, whether they are published or not. The documents may come from teaching and research institutions in France or abroad, or from public or private research centers.
L'archive ouverte pluridisciplinaire HAL, est destinée au dépôt et à la diffusion de documents scientifiques de niveau recherche, publiés ou non, émanant des établissements d'enseignement et de recherche français ou étrangers, des laboratoires publics ou privés. 


\title{
The Impact of the Particle Size Distribution of Organic Additives on the Microstructure of a Clay Ceramic and Its Thermal and Mechanical Properties
}

\author{
Pierre-Marie Nigay ${ }^{1}$; Ange Nzihou ${ }^{2}$; and Thierry Cutard ${ }^{3}$
}

\begin{abstract}
In this study, the structure-property relationships of a clay ceramic with calibrated particles (10 or $50 \mu \mathrm{m})$ of polymethyl methacrylate (PMMA) were investigated to improve both the thermal and mechanical properties of fired clay bricks incorporating organic wastes. The structure was characterized using differential thermal, thermomechanical, and computed tomography analysis. It was found that the addition of 10- or 50- $\mu \mathrm{m}$ particles of PMMA resulted in a same 11\% decrease of the thermal conductivity during the extrusion process. The Young's modulus also increased by $23 \%$ during the extrusion process with the addition of $50-\mu \mathrm{m}$ particles. However, the addition of $10-\mu \mathrm{m}$ particles resulted in a greater increase of the Young's modulus by $34 \%$. The calibrated particles of PMMA were then found to transform into porosity during firing of the clay ceramic. Typically, the pore size of the clay ceramic corresponded to the particle size of the calibrated particles of PMMA. The improvement of the thermal and mechanical properties that was obtained during the extrusion process was conserved in the form of porosity with a reduction of the median pore size after the firing process. Hence, the current results indicate that the thermal and mechanical properties of fired clay bricks can be improved at the same time using a wide range of organic wastes if the organic wastes are subjected to grinding prior to incorporation in the mixture. They also suggest that organic wastes can reduce the environmental impact of fired clay bricks with an energetic contribution of $73.8 \%$.
\end{abstract}

Author keywords: Clay bricks; Organic additives; Porosity; Thermal conductivity; Young's modulus; Energetic contribution.

\section{Introduction}

The recycling of industrial and urban waste has recently gained momentum in the field of building materials (Zhang 2013; Bories et al. 2014). The addition of waste to the composition of fired clay bricks has positive effects on the performances. Moreover, waste is a potential energy carrier in the industrial process of fired clay bricks.

The waste comes from wood, paper, or oil industries. It is mostly used for the high organic fraction beyond 60\% (Phonphuak and Chindaprasirt 2014). The addition ranges from 1 to $30 \%$ depending on the organic fraction (Monteiro and Vieira 2014). On the other hand, the particle size ranges from 1 to $4 \mathrm{~mm}$ to keep the process unchanged (Andreola et al. 2001).

The organic additives are then subjected to combustion during firing of the clay bricks at temperatures up to $1,000^{\circ} \mathrm{C}$ (Demir 2008). The combustion of these organic additives also results in

${ }^{1}$ Postdoctoral Researcher, Centre Recherche d'Albi en génie des Procédés des Solides Divisés, de l'Énergie et de l'Environnement, Ecole des Mines d'Albi, Campus Jarlard, Route de Teillet, 81013 Albi Cedex 09, France (corresponding author). ORCID: https://orcid.org/0000-0003-2204 -6205. E-mail: pierre-marie.nigay@mines-albi.fr

${ }^{2}$ Professor, Centre Recherche d'Albi en génie des Procédés des Solides Divisés, de l'Énergie et de l'Environnement, Ecole des Mines d'Albi, Campus Jarlard, Route de Teillet, 81013 Albi Cedex 09, France. E-mail: ange.nzihou@mines-albi.fr

${ }^{3}$ Professor, Institut Clément Ader, Ecole des Mines d'Albi, Campus Jarlard, Route de Teillet, 81013 Albi Cedex 09, France. E-mail: thierry .cutard@mines-albi.fr a porosity formation within the bricks. Hence, the clay bricks have a higher volume fraction of pores after the firing process (Muñoz Velasco et al. 2015).

The insulating behavior of air in the newly formed pores improves the thermal properties of the fired clay bricks (Dondi et al. 2004; Mendívil et al. 2017). It has been shown that the porosity resulting from the combustion of waste from oil industry decreased the thermal conductivity by $20 \%$ (Eliche-Quesada et al. 2012). The thermal conductivity also decreased by $36 \%$ in another study where sawdust was used as the pore-forming agent (Bánhidi and Gömze 2008). However, that improvement of the thermal conductivity is always obtained along with a loss in the mechanical strength (Bories et al. 2015). Typically, these pores resulting from the combustion of organic additives are acting like defects (Ukwatta and Mohajerani 2017). It has been shown that the mechanical strength of fired clay bricks decreased by $4 \%$ when using sludge from wastewater treatment as the pore-forming agent (Monteiro et al. 2008). Some other studies also revealed that the pores resulting from the combustion of sawdust can result in a critical loss of $27 \%$ (Ducman and Kopar 2001).

The combustion of the organic additives results in an extensive release of heat within the tunnel kilns. The temperature increase provides an energetic contribution to the process and energy savings. According to the literature, the energy savings can reach up to $58 \%$ using a $5 \%$ by weight addition of cigarette butts (Mohajerani et al. 2016). The recycling of industrial and urban waste in fired clay bricks is then a relevant concept. It provides an improvement of the thermal properties as well as energy savings. The loss of strength is a major issue for such materials. However, Korah et al. (2016) have shown in a recent study that the addition of organic additives with smaller particles can result in the formation of smaller pores. These small pores resulting from the combustion of the organic additives may act as minor defects and prevent the loss 
of strength, as shown by Nigay et al. (2017) for the small pores resulting from mineralogical transformations of the clay.

The objective of this study is to investigate the impact of the particle size distribution of organic additives on the microstructure of a clay ceramic and its thermal and mechanical properties. Hence, the study focuses on a $6 \%$ by weight addition of a same organic additive in one form of $10-\mu \mathrm{m}$ particles and one form of $50-\mu \mathrm{m}$ particles. The particle size distribution is compared with the pore size distribution. The volume fraction and the size of the newly formed pores are also related to the evolution of the thermal conductivity and of the Young's modulus during the firing process. Therefore, the study should provide a useful insight into how the microstructure of fired clay bricks can be controlled by the particle size distribution of organic additives to improve both the thermal and mechanical properties.

\section{Materials and Methods}

\section{Raw Materials}

The clay was extracted from a quarry in the Toulouse area (France). The lumps of clay were ground into smaller lumps of approximately $3 \mathrm{~mm}$ using a rolling mill (LA 1527, Vicentini, Cavazzale, Italy). The composition, measured via inductively coupled plasma-atomic emission spectroscopy (ICP-AES) (Ultima 2, Jobin Yvon, Longjumeau, France), showed a predominance of silicon and aluminum oxides with smaller concentrations of calcium, iron, and potassium oxides.

The organic additives consisted of a thermoplastic polymer of polymethyl methacrylate (PMMA). They were obtained from Microbeads Company (Skedsmokorset, Norway) in the form of $10-\left(\mathrm{MB}_{10}\right)$ and $50-\mu \mathrm{m}\left(\mathrm{MB}_{50}\right)$ microbeads. The elemental composition that was determined using organic elemental analysis (Flash 2000, Thermo Fisher Scientific, Waltham, Massachusetts) is summarized in Table 1 . The results show that the $\mathrm{MB}_{10}$ and $\mathrm{MB}_{50}$ additives had the same composition. They were both composed of organic elements such carbon, oxygen, and hydrogen with a minor amount of nitrogen.

The heating value of the organic additives was measured using an oxygen bomb calorimeter (C 6000, IKA, Wilmington, North Carolina). The measurements were performed under adiabatic mode with pill samples that were compressed in a press machine. The lower heating value of the organic additives was estimated by subtracting the latent heat of vaporization from the results of the higher heating value. The $\mathrm{MB}_{10}$ and $\mathrm{MB}_{50}$ additives both had a lower heating value of $23,291 \mathrm{~J} / \mathrm{g}$.

The particle size distribution of the organic additives was measured by laser granulometry analysis using a Malvern Mastersizer 3,000 instrument (Malvern, United Kingdom). The results in Fig. 1 confirm the particle size of the organic additives. The $\mathrm{MB}_{10}$ and $\mathrm{MB}_{50}$ additives had an average particle size of 10 and $50 \mu \mathrm{m}$, respectively.

Table 1. Elemental Composition of the $\mathrm{MB}_{10}$ and $\mathrm{MB}_{50}$ Additives with the Concentrations in Carbon, Hydrogen, Oxygen, Nitrogen, and Sulfur Elements

\begin{tabular}{lccccc}
\hline & \multicolumn{5}{c}{ Concentration (\% by weight) } \\
\cline { 2 - 6 } Sample & $\mathrm{C}$ & $\mathrm{H}$ & $\mathrm{O}$ & $\mathrm{N}$ & $\mathrm{S}$ \\
\hline $\mathrm{MB}_{10}$ & 59.9 & 7.7 & 32.2 & 0.2 & 0.0 \\
$\mathrm{MB}_{50}$ & 59.8 & 7.9 & 32.1 & 0.2 & 0.0 \\
\hline
\end{tabular}

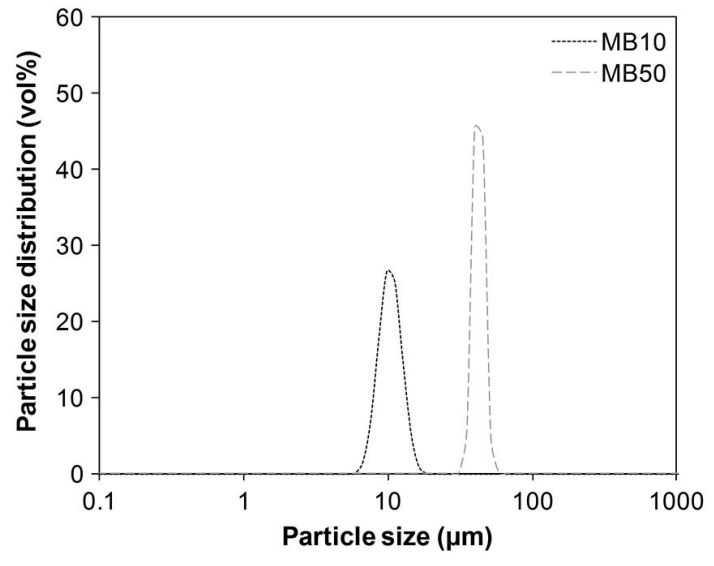

Fig. 1. Particle size distribution of $\mathrm{MB}_{10}$ and $\mathrm{MB}_{50}$ additives

\section{Processing of the Clay Ceramic}

The clay ceramic was produced from different mixtures of clay with organic additives and water. The percentage of organic additives was determined from the results of Korah et al. (2016) to investigate the impact of the particle size distribution of the organic additives with yet an optimization of the percentage of addition for the thermal and the mechanical properties. Hence, the mixtures were prepared by mixing $10 \mathrm{~kg}$ of clay with $6 \%$ by weight of organic additives $\left(\mathrm{MB}_{10}\right.$ or $\left.\mathrm{MB}_{50}\right)$. Some water was also added to the mixtures until an 800,000 $\mathrm{Pa}$ (8-bar) pressure of extrusion was obtained. Subsequently, the mixtures were extruded in the form of blocks with dimensions of $180 \times 80 \times 18 \mathrm{~mm}^{3}$ for a water content of $17 \%$ by weight. The blocks were dried at temperatures of 25 , 65 , and $105^{\circ} \mathrm{C}$ for $24 \mathrm{~h}$. Finally, the different samples were prepared from the dried blocks using P80, P120, P180, and P280 SiC abrasive papers (Buehler, Uzwil, Switzerland). Some of the samples were also fired in a furnace (Controller P320, Nabertherm, Lilienthal, Germany) at temperatures given in the next sections.

\section{Characterization of the Microstructure}

The mass loss and the heat flow of the clay ceramic were determined using differential thermal analyses (DTA). The unfired samples were analyzed in the form of 200-mg cylinders with a Setaram 92 apparatus (Caluire, France). The data were collected in air atmosphere at temperatures between 30 and $1,100^{\circ} \mathrm{C}$ using a $5^{\circ} \mathrm{C} / \mathrm{min}$ heating rate.

The deformation was measured as a function of the temperature using thermomechanical analyses (TMA). The unfired samples were analyzed as 200-mg cylinders in a Setsys 16/18 instrument (Setaram, Caluire, France). The data were collected in air atmosphere at temperatures between 30 and $1,100^{\circ} \mathrm{C}\left(5^{\circ} \mathrm{C} / \mathrm{min}\right.$ heating rate). In fact, the DTA and TMA analyses were performed under the same conditions to provide an accurate estimate of the bulk density (Baillez and Nzihou 2004). The bulk density $\left[\rho_{(\mathrm{T})}\right]$ was estimated from Eq. (1) using the mass loss, the shrinkage, the initial mass $\left(m_{0}\right)$, the initial length $\left(l_{0}\right)$, and the initial radius $\left(r_{0}\right)$ of the samples

$$
\rho_{(\mathrm{T})}=\frac{m_{0}\left(1-\operatorname{Massloss}_{(\mathrm{T})}\right)}{\pi r_{0}^{2} l_{0}\left(1-\operatorname{Shrinkage}_{(\mathrm{T})}\right)^{3}}
$$

The dependence of the pore volume fraction on the firing temperature $\left[\varepsilon_{(T)}\right]$ was estimated from Eq. (2) (Nigay et al. 2017). The estimates were obtained using the bulk density $\left[\rho_{(\mathrm{T})}\right]$ and the true density of the particles $\left(\rho_{\text {True }}\right)$. The true density of the particles 
was measured by Helium pycnometer analyses after firing at $1,100^{\circ} \mathrm{C}$ and grinding to remove the porosity. The value was equal to $2.72 \mathrm{~g} / \mathrm{cm}^{3}$

$$
\varepsilon_{(\mathrm{T})}=1-\frac{\rho_{(\mathrm{T})}}{\rho_{\text {True }}}
$$

The three-dimensional (3D) representations of the porosity were obtained by X-ray tomography analysis using a Synchrotron facility (ESRF Grenoble). The samples were scanned in the form of 200-mg cylinders after firing at a temperature of $950^{\circ} \mathrm{C}$.

\section{Determination of the Thermal Conductivity}

The thermal conductivity was measured using a Hot Disk AB TPS 2500 system (Gothenburg, Sweden). The measurements were carried out with duplicate samples of $30 \times 30 \times 5 \mathrm{~mm}^{3}$ after firing at $30,200,400,600,700,800,900,1,000$, and $1,100^{\circ} \mathrm{C}$. In this way, the evolution of the thermal conductivity could be compared to the evolution of the volume fraction of pores with the firing temperature.

\section{Determination of the Young's Modulus and of the Flexural Strength}

The Young's modulus was measured as a function of the temperature using a resonant frequency analyzer (RFDA HT650, IMCE, Genk, Belgium) with unfired samples of $60 \times 30 \times 5 \mathrm{~mm}^{3}$. The values of the Young's modulus were calculated from the fundamental frequency of resonance and the dimensions of the samples. They could be obtained in a continuous way at temperatures between 30 and $1,050^{\circ} \mathrm{C}$.

The flexural strength was also measured using three-point bending tests after firing at a temperature of $950^{\circ} \mathrm{C}$. The measurements were performed with flexural specimens of $60 \times 30 \times 5 \mathrm{~mm}^{3}$. The specimens were loaded in an Instron 5800R machine (Norwood, Massachusetts) with a 40-mm loading span and a 500-N load cell at a $1 \mathrm{~mm} / \mathrm{min}$ displacement rate

$$
\sigma_{f}=\frac{3 F_{\mathrm{Max}} L}{2 B H^{2}}
$$

The flexural strength of the clay ceramic $\left(\sigma_{f}\right)$ was estimated from Eq. (3), where $F_{\text {Max }}$ is the maximum force, $L$ is the loading span, $B$ is the breadth, and $H$ is the height of the samples (ASTM 2010).

\section{Determination of the Energetic Contribution}

The energetic contribution of the organic additives was determined by DTA. The energy released by thermal degradation of the organic additives was estimated by integration of the exothermic peaks on the heat flow. The electrical value was transposed in an energetic value using a calibration with indium, tin, zinc, and aluminum standards. Furthermore, the energy required by the firing process of the clay ceramic was estimated by integration of the dehydration, dehydroxylation, and decarbonation peaks, in addition to the energy used to reach the temperature of $950^{\circ} \mathrm{C}$. The energetic contribution was finally calculated as the quantity of energy released on the quantity of energy required.

\section{Results}

\section{Thermal Behavior of the Clay Ceramic}

The heat flow of the clay ceramic is presented in Fig. 2. The results show that the clay ceramic without organic additives is subjected to

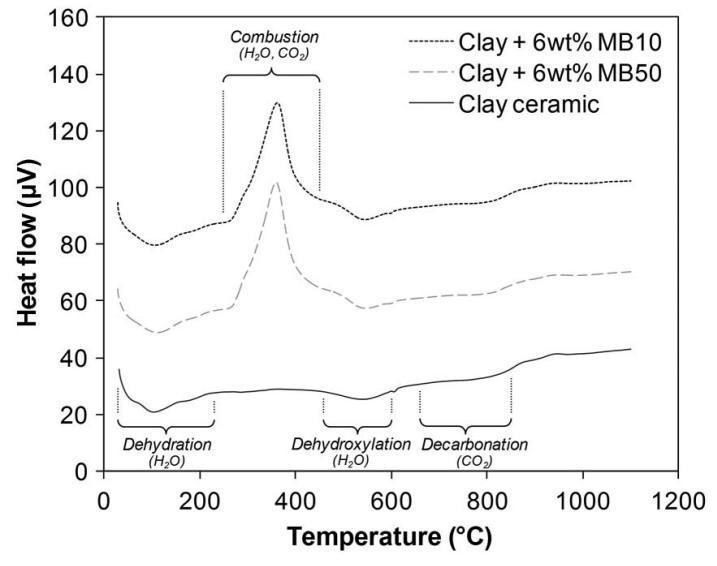

Fig. 2. Heat flow of the clay ceramic and of the clay ceramic with a $6 \%$ by weight addition of $\mathrm{MB}_{10}$ and $\mathrm{MB}_{50}$ additives

dehydration at temperatures between 30 and $200^{\circ} \mathrm{C}$. The release of interposition water that remained in the pores, along with the release of hygroscopic water that was absorbed on the clay particles, involves a $304 \mathrm{~J} / \mathrm{g}$ absorption of energy. It can be observed that the clay ceramic is also subjected to dehydroxylation at temperatures between 450 and $600^{\circ} \mathrm{C}$. The modification of the clay minerals, which is associated with a release of constitution water, involves a $169 \mathrm{~J} / \mathrm{g}$ absorption of energy. Finally, the results show that the calcium carbonates from the clay mixture are subjected to decarbonation by the end of the firing process. This results in a $157 \mathrm{~J} / \mathrm{g}$ adsorption of energy between 650 and $850^{\circ} \mathrm{C}$. More details on the mineralogical transformations of the clay ceramic can be found in Nigay et al. (2017)

Concurrently, the $\mathrm{MB}_{50}$ additive combusts in the clay ceramic from 250 to $450^{\circ} \mathrm{C}$. The combustion results in a transformation of the PMMA into water and carbon dioxide. The exothermic reaction of combustion involves a $1,160 \mathrm{~J} / \mathrm{g}$ release of energy during the firing process. It is important to note that this amount of energy, released in the form of heat, is greater than the amount of energy that is required by the firing transformations. In fact, the combustion of PMMA occurs on a free range of temperatures. The usual transformations of the clay are then not affected by the combustion of $\mathrm{MB}_{50}$ additive. The $\mathrm{MB}_{10}$ additive is subjected to combustion on the same range of temperature. The combustion of $\mathrm{MB}_{10}$ additive also leads to a similar 1,143 J/g release of energy. This is due to the fact that $\mathrm{MB}_{10}$ and $\mathrm{MB}_{50}$ additives have a same composition of PMMA with yet a different particle size. The particle size of organic additives then has no effect on the thermal behavior of the clay ceramic. In fact, the thermal behavior of the clay ceramic only depends on the composition of the organic additives.

The mass loss of the clay ceramic is shown in Fig. 3. These results complete the previous results of the heat flow. In fact, the water release associated with the dehydration induces a mass loss of $3 \%$ by weight between 30 and $200^{\circ} \mathrm{C}$. A mass loss of $2 \%$ by weight also results from the release of constitution water during the dehydroxylation at temperatures between 450 and $600^{\circ} \mathrm{C}$. The release of carbon dioxide associated with the decarbonation also leads to a mass loss of $4 \%$ by weight between 650 and $850^{\circ} \mathrm{C}$. Therefore, the clay ceramic is subjected to a mass loss of $9 \%$ by weight during the entire process of firing at temperatures up to $950^{\circ} \mathrm{C}$.

The results of the mass loss also confirm the previous results of the thermal behavior of the $\mathrm{MB}_{50}$ additive in the clay ceramic. In fact, the release of water and carbon dioxide associated with 


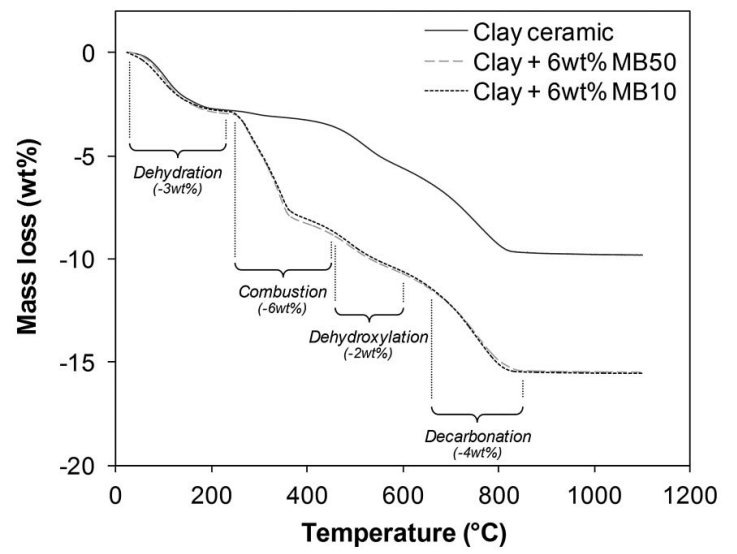

Fig. 3. Mass loss of the clay ceramic and of the clay ceramic with a $6 \%$ by weight addition of $\mathrm{MB}_{50}$ and $\mathrm{MB}_{10}$ additives

the combustion of the $\mathrm{MB}_{50}$ additive induces a mass loss of $6 \%$ by weight at temperatures between 250 and $450^{\circ} \mathrm{C}$. The $6 \%$ by weight loss corresponds to the $6 \%$ by weight addition of $\mathrm{MB}_{50}$ in the clay ceramic. This means that the combustion of PMMA induces a full elimination of the $\mathrm{MB}_{50}$ additive. The $\mathrm{MB}_{50}$ additive is fully eliminated as a result of the pure organic nature of PMMA. The $\mathrm{MB}_{10}$ additive is subjected to a same combustion as the $\mathrm{MB}_{50}$ additive during the firing process. The combustion of the $\mathrm{MB}_{10}$ additive also leads to a same mass loss as the combustion of the $\mathrm{MB}_{50}$ additive. Hence, the particle size of the organic additives has no effect on the mass loss of the clay ceramic. The mass loss only depends on the percentage of organic additives along with their organic fraction.

The deformation of the clay ceramic is shown in Fig. 4. The results indicate that the clay ceramic without organic additives is subjected to shrinkage during the dehydration. In fact, the water release associated with the dehydration results in a $0.1 \%$ by volume shrinkage of the clay ceramic from 30 to $200^{\circ} \mathrm{C}$. From 450 to $600^{\circ} \mathrm{C}$, the dehydroxylation of the clay minerals induces a $0.1 \%$ by volume expansion of the clay ceramic. A sharp expansion of $0.3 \%$ is also associated with the $\alpha \rightarrow \beta$ quartz inversion at around $600^{\circ}$ C. It is important to note that the reverse transformation that occurs during the cooling induces a formation of major defects with the larger shrinkage of quartz than clay particles (Tarvornpanich et al. 2008).

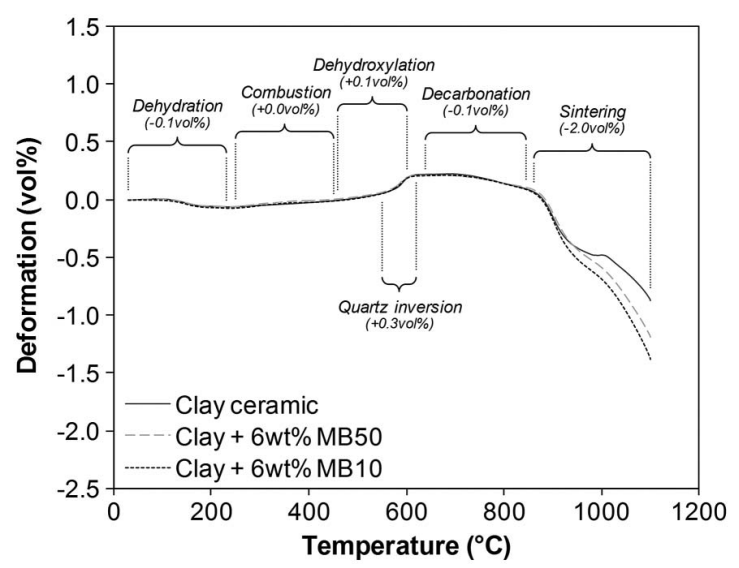

Fig. 4. Deformation of the clay ceramic and of the clay ceramic with a $6 \%$ by weight addition of $\mathrm{MB}_{50}$ and $\mathrm{MB}_{10}$ additives
Finally, the sintering induces an important shrinkage of the clay ceramic with the formation of necks between the clay particles. The shrinkage is still limited to $2 \%$ by volume owing to the decarbonation of calcium carbonates at temperatures up to $850^{\circ} \mathrm{C}$.

The $\mathrm{MB}_{50}$ additive is subjected to combustion in the clay ceramic at temperatures between 250 and $450^{\circ} \mathrm{C}$. However, the combustion of the $\mathrm{MB}_{50}$ additive does not result in any deformation of the clay ceramic. The deformation is not affected by the combustion of the $\mathrm{MB}_{10}$ additive either in this range of temperatures. In fact, the organic additives only lead to a slight increase of the shrinkage during the sintering process. The shrinkage is increased by $0.3 \%$ by volume in the case of a $6 \%$ by weight addition of $\mathrm{MB}_{50}$ additives. Similarly, the $6 \%$ by weight addition of $\mathrm{MB}_{10}$ additives induces a $0.5 \%$ by volume increase of the shrinkage. The deformation of the clay ceramic is then not significantly affected by the particle size distribution of the organic additives. Furthermore, this slight increase of the shrinkage occurs at temperatures between 950 and $1,100^{\circ} \mathrm{C}$. This means that the organic additives do not induce any deformation of the clay ceramic at the standard temperature of firing (i.e., $950^{\circ} \mathrm{C}$ ). Overall, the clay ceramic is only affected by the mass loss of the organic additives, which depends on the percentage of addition and their organic fraction.

\section{Microstructure of the Clay Ceramic}

The porosity of the clay ceramic is presented in Fig. 5. It can be observed that the clay ceramic without organic additives has a volume fraction of pores equal to $24 \%$ by volume (bulk density of $2,061 \mathrm{~kg} \cdot \mathrm{m}^{-3}$ ) prior to firing (i.e., at $30^{\circ} \mathrm{C}$ ). In fact, the air remaining in the clay ceramic mixture is trapped in the form of pores during the extrusion. This porosity also increases with the water release during the drying process. Moreover, the dehydration of the clay ceramic induces a $2 \%$ by volume formation of porosity from 30 to $200^{\circ} \mathrm{C}$ (decrease of the bulk density from 2,061 to $2,011 \mathrm{~kg} \cdot \mathrm{m}^{-3}$ ). The porosity also increases by $2 \%$ by volume during the dehydroxylation at temperatures between 450 and $600^{\circ} \mathrm{C}$ (decrease of the bulk density from 1,996 to $1,955 \mathrm{~kg} \cdot \mathrm{m}^{-3}$ ). The decarbonation of the calcium carbonates also results in a $3 \%$ by volume formation of porosity between 650 and $850^{\circ} \mathrm{C}$ (decrease of the bulk density from 1,943 to $1,876 \mathrm{~kg} \cdot \mathrm{m}^{-3}$ ). In fact, the porosity only decreases by $2 \%$ by volume during the sintering from 850 to $1,100^{\circ} \mathrm{C}$ (increase of the bulk density from 1,876 to $1,927 \mathrm{~kg} \cdot \mathrm{m}^{-3}$ ). This means that the clay ceramic conserves a porosity of $30 \%$ by volume (bulk density of $1,902 \mathrm{~kg} \cdot \mathrm{m}^{-3}$ ) after firing at $950^{\circ} \mathrm{C}$.

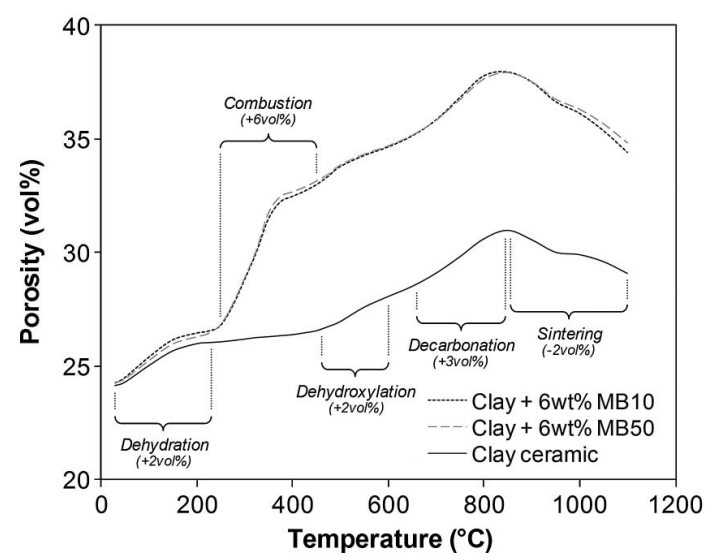

Fig. 5. Porosity of the clay ceramic and of the clay ceramic with a $6 \%$ by weight addition of $\mathrm{MB}_{50}$ and $\mathrm{MB}_{10}$ additives 
The combustion of the $6 \%$ by weight of $\mathrm{MB}_{50}$ additive induces a $6 \%$ by volume increase of the porosity (decrease of the bulk density from 1,928 to $1,814 \mathrm{~kg} \cdot \mathrm{m}^{-3}$ ). It was shown previously that the combustion of $\mathrm{MB}_{50}$ additive does not induce any deformation of the clay ceramic. Hence, the porosity formation of the clay ceramic results from the mass loss of the $\mathrm{MB}_{50}$ additive. The porosity formation occurs on the free range of temperature from 250 to $450^{\circ} \mathrm{C}$. Therefore, the porosity formations associated with the clay transformations are not modified by the porosity formation associated with the combustion of $\mathrm{MB}_{50}$. It is important to note that the porosity resulting from the combustion of $\mathrm{MB}_{50}$ is added and conserved up to $1,100^{\circ} \mathrm{C}$. This means that the porosity has an additive and conservative behavior during the entire process of firing. The $\mathrm{MB}_{10}$ additive results in a same formation of porosity because its combustion induces a same mass loss ( $6 \%$ by weight) as the combustion of $\mathrm{MB}_{50}$ additive. The particle size of the organic additives has no effect on the porosity of the clay ceramic. The porosity depends on the mass loss of the organic additives during the firing process. The percentage of porosity is then controlled by the percentage of organic additives along with their organic fraction.

The 3D representation of the porosity is presented in Fig. 6. The clay ceramic without organic additives has a microstructure of clay with porosity sheets. As shown by Korah et al. (2016), the clay is compressed in the form of sheets during the extrusion. The air remaining in the clay mixture is then compressed as porosity sheets between the sheets of clay. It is important to note that the porosity sheets forming during the extrusion are not eliminated by the formation of pores during the firing. The large sheets of porosity that correspond to major defects are also conserved during the sintering up to $950^{\circ} \mathrm{C}$.

The clay ceramic with a $6 \%$ by weight addition of $\mathrm{MB}_{50}$ additives does not contain any sheets of porosity. In fact, the $\mathrm{MB}_{50}$ additive induces an elimination of the porosity sheets soon after the extrusion process. The small particles of $\mathrm{MB}_{50}$ additive increase the compression of the clay. Therefore, the air remaining in the clay mixture is compressed between the sheets of clay in the form of smaller pores during the extrusion process. The clay ceramic with a $6 \%$ by weight addition of $\mathrm{MB}_{50}$ additive also contains spherical pores with a $50 \mu \mathrm{m}$ diameter. The $50-\mu \mathrm{m}$ diameter of these pores corresponds to the $50-\mu \mathrm{m}$ size of the $\mathrm{MB}_{50}$ additive. Hence, these pores represent the $6 \%$ by volume formation of porosity resulting from the combustion of $\mathrm{MB}_{50}$ additive during the firing process. The pores associated with the combustion of the organic additive represent the voids released by their particles in the microstructure.

The clay ceramic with a $6 \%$ by weight addition of $\mathrm{MB}_{10}$ additives does not contain any sheets of porosity. Moreover, the $10-\mu \mathrm{m}$ particles of $\mathrm{MB}_{10}$ additive induce a formation of smaller $10-\mu \mathrm{m}$ pores than those of $\mathrm{MB}_{50}$ additive. It results in a larger reduction of the pore size diameter of the clay ceramic after the firing process. The type of porosity is eventually controlled by the particle size of the organic additives. On the other hand, the organic fraction of the additives provides a control of the percentage of porosity.

\section{Thermal Properties of the Clay Ceramic}

The dependence of the thermal conductivity on the firing temperature of the clay ceramic is presented in Fig. 7. The results show that the clay ceramic without organic additives has a thermal conductivity of $1.07 \mathrm{~W} / \mathrm{m} \cdot \mathrm{K}$ prior to firing (i.e., at $30^{\circ} \mathrm{C}$ ). As shown by Nigay et al. (2017), this value corresponds to a combination between the high thermal conductivity of the clay and the low thermal conductivity of air in the porosity sheets. The impact of air is also enhanced in this direction of the thermal gradient of the walls with the anisotropy of the porosity sheets. The thermal conductivity

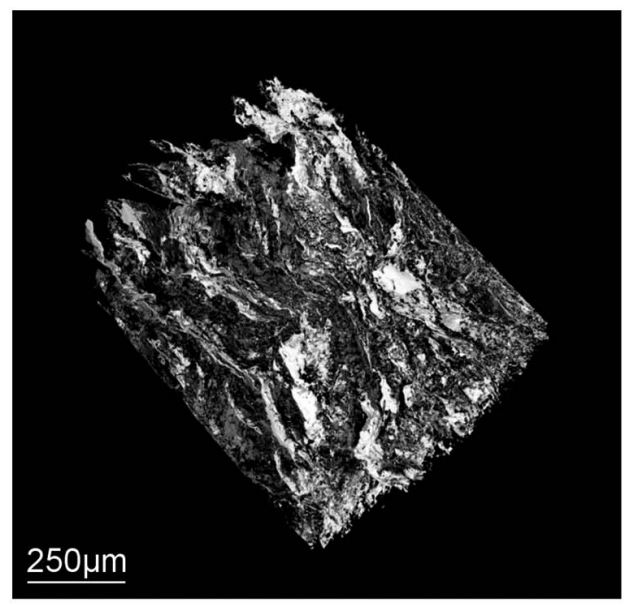

(a)

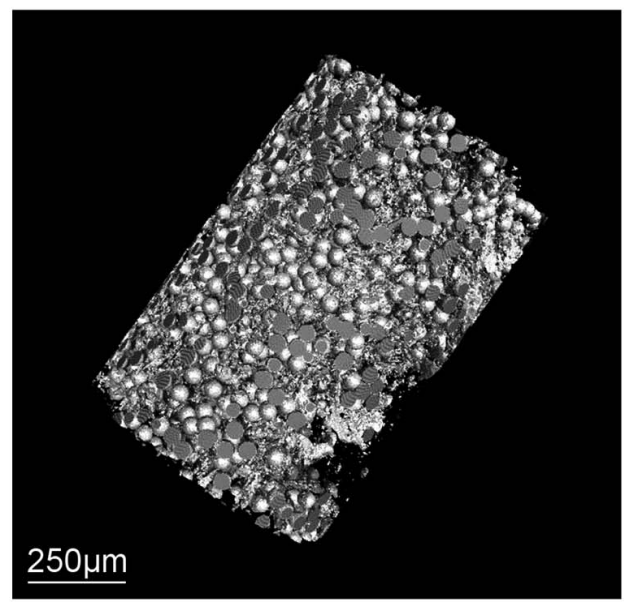

(b)

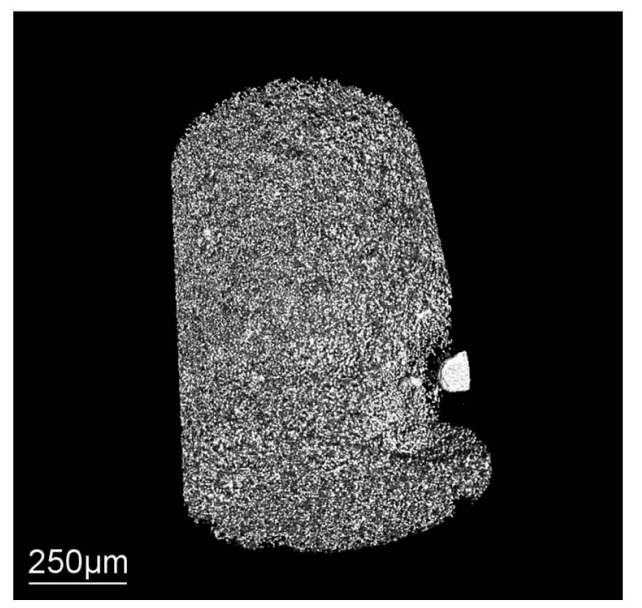

(c)

Fig. 6. X-ray tomography representation of (a) porosity of the clay ceramic; clay ceramic with a $6 \%$ by weight addition of (b) $\mathrm{MB}_{50}$ additive and (c) $\mathrm{MB}_{10}$ additive

decreases by $30 \%$ during the firing process of the clay ceramic up to $850^{\circ} \mathrm{C}$. The decrease is associated with the $7 \%$ by volume formation of porosity due to the dehydration, dehydroxylation, and decarbonation. In fact, the thermal conductivity decreases as a result of the low thermal conductivity of air in the newly formed pores. The thermal conductivity only increases with the sintering 


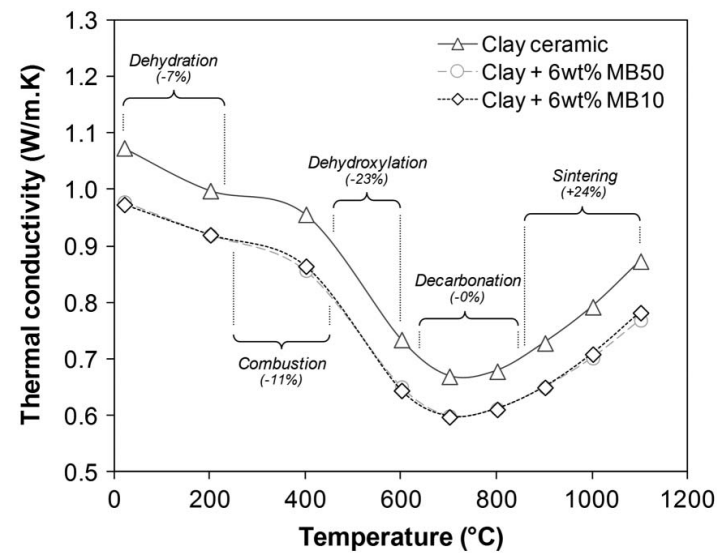

Fig. 7. Dependence of the thermal conductivity on the firing temperature of the clay ceramic and of the clay ceramic with a $6 \%$ by weight addition of $\mathrm{MB}_{50}$ and $\mathrm{MB}_{10}$ additives

up to $1,100^{\circ} \mathrm{C}$. The greater fraction of clay results in a $24 \%$ increase of the thermal conductivity.

The $6 \%$ by weight addition of $\mathrm{MB}_{50}$ additive induces an $11 \%$ decrease of the thermal conductivity prior to firing (i.e., at $30^{\circ} \mathrm{C}$ ). The thermoplastic polymer of PMMA has, in accordance with the literature, a relatively low thermal conductivity. Hence, the insulating behavior of $\mathrm{MB}_{50}$ additive decreases the thermal conductivity of the clay ceramic soon after the extrusion process. The combustion of $\mathrm{MB}_{50}$ additive leads to a $6 \%$ by volume increase of the porosity between 250 and $450^{\circ} \mathrm{C}$. However, the newly formed pores do not induce a significant decrease of the thermal conductivity. The thermal conductivity of air in the newly formed pores is equivalent to that of the PMMA. The impact of the porosity on the thermal conductivity of the clay ceramic is then all provided during the extrusion process. But, the transformation of $\mathrm{MB}_{50}$ additive into porosity allows a conservation of the initial decrease of the thermal conductivity. The porosity has indeed an additive and a conservative behavior on the entire process of firing. The $11 \%$ decrease of the thermal conductivity during the extrusion process is then conserved during the firing process up to $1,100^{\circ} \mathrm{C}$.

The $6 \%$ by weight addition of $\mathrm{MB}_{10}$ additive results in a same decrease of the thermal conductivity as that of $\mathrm{MB}_{50}$ additive during the extrusion. The combustion of the $\mathrm{MB}_{10}$ additive also results in a same conservation of the initial decrease in the thermal conductivity during the firing. This means that the particle size of the organic additives has no effect on the thermal conductivity. The thermal conductivity of the clay ceramic is related to the percentage of porosity after firing. Therefore, the thermal conductivity is controlled by the percentage of organic additives along with their organic fraction.

\section{Mechanical Properties of the Clay Ceramic}

The dependence of the Young's modulus on the firing temperature of the clay ceramic is shown in Fig. 8. The results indicate that the clay ceramic without organic additives has a Young's modulus of $7.5 \mathrm{GPa}$ prior to firing (i.e., at $30^{\circ} \mathrm{C}$ ). This value results from the formation of clay sheets during the extrusion. However, it is also minimized by the large sheets of porosity which are acting as defects. The firing process does not induce a significant decrease of the Young's modulus at temperatures between 30 and $850^{\circ} \mathrm{C}$. The dehydration, dehydroxylation and decarbonation leads to a porosity formation of $7 \%$ by volume in this range of temperatures. But, the pores associated with the firing transformations are smaller than the

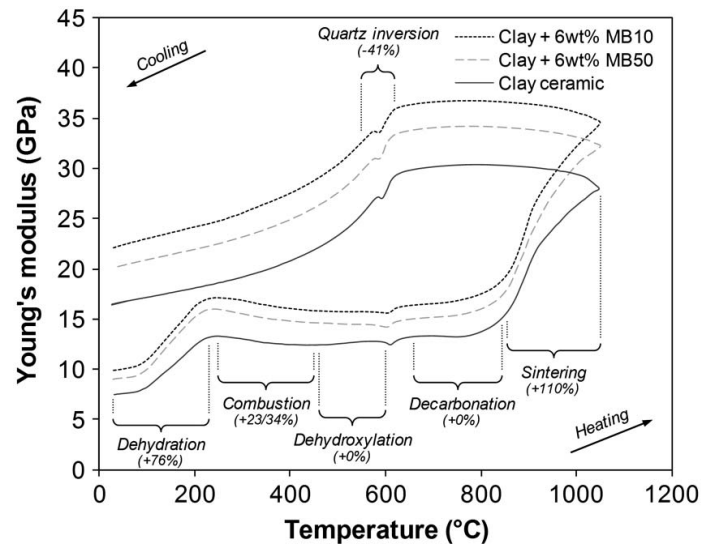

Fig. 8. Dependence of the Young's modulus on the firing temperature of the clay ceramic and of the clay ceramic with a $6 \%$ by weight addition of $\mathrm{MB}_{50}$ and $\mathrm{MB}_{10}$ additives

large porosity sheets from the extrusion. This result suggests that a formation of smaller pores than the defects of the microstructure allows a conservation of the Young's modulus. On the other hand, the densification results in a $110 \%$ increase of the Young's modulus between 850 and $1,050^{\circ} \mathrm{C}$. This means that the Young's modulus only decreases with the $\beta \rightarrow \alpha$ quartz inversion during the cooling.

The $6 \%$ by weight addition of $\mathrm{MB}_{50}$ additive induces a $23 \%$ increase of the Young's modulus prior to firing (i.e., at $30^{\circ} \mathrm{C}$ ). The thermoplastic polymer of PMMA has no significant stiffness compared with the clay. However, the small particles of $\mathrm{MB}_{50}$ additive reduce the pore size diameter of the clay ceramic. Hence, the smaller pores resulting from the extrusion have a lower impact on the Young's modulus. The Young's modulus is then increased by the $\mathrm{MB}_{50}$ additive soon after the extrusion. The combustion of the $\mathrm{MB}_{50}$ additive also leads to a $6 \%$ by volume formation of porosity during the firing process. But, the transformation of the $\mathrm{MB}_{50}$ additive into pores does not decrease the Young's modulus. The Young's modulus is not decreased because the stiffness of the pores is equivalent to that of PMMA. The impact of the newly formed pores on the Young's modulus is then all provided during the extrusion process. However, the transformation of $\mathrm{MB}_{50}$ additive into porosity allows a conservation of the initial increase of the Young's modulus. The porosity has indeed an additive and a conservative behavior on the entire process of firing. The $23 \%$ increase of the Young's modulus during the extrusion process is then conserved during heating and cooling.

The $6 \%$ by weight addition of $\mathrm{MB}_{10}$ additive also results in an increase of the Young's modulus soon after extrusion. However, the $\mathrm{MB}_{10}$ additive induces a greater increase of $34 \%$ due to a smaller $10-\mu \mathrm{m}$ size of the particles. This means that the particle size of the organic additives has a major impact on the Young's modulus. In fact, the Young's modulus depends on the percentage and the size of the pores after the firing process. The Young's modulus is then controlled by the percentage of organic additives along with their particle size distribution.

The flexural strengths of the clay ceramic after firing at $950^{\circ} \mathrm{C}$ are given in Table 2. The results confirm the impact of the particle size of the organic additives on the Young's modulus. The 50- $\mu \mathrm{m}$ particles of the $\mathrm{MB}_{50}$ additives induce a $26 \%$ increase of the flexural strength using a $6 \%$ by weight addition. The clay ceramic with a $6 \%$ by weight addition of $\mathrm{MB}_{50}$ additives has then a flexural strength of $15.4 \mathrm{MPa}$ after the firing process. On the other hand, the $6 \%$ by weight addition of $\mathrm{MB}_{10}$ additive with smaller particles of $10 \mu \mathrm{m}$ results in a greater increase of the flexural strength by 
Table 2. Flexural Strength of the Clay Ceramic and of the Clay Ceramic with a $6 \%$ by Weight Addition of $\mathrm{MB}_{50}$ and $\mathrm{MB}_{10}$ Additives

\begin{tabular}{lc}
\hline Samples & Flexural strength (MPa) \\
\hline Clay ceramic & $12.2 \pm 0.2$ \\
Clay $+6 \%$ by weight $\mathrm{MB}_{10}$ & $15.4 \pm 0.2$ \\
Clay $+6 \%$ by weight $\mathrm{MB}_{50}$ & $16.2 \pm 0.1$ \\
\hline
\end{tabular}

$33 \%$. The clay ceramic then has a flexural strength of $16.2 \mathrm{MPa}$ using a $6 \%$ by weight addition of $\mathrm{MB}_{10}$ additive.

\section{Energy Balance of the Clay Ceramic}

The energy balance of the clay ceramic is given in Table 3 . The results indicate a $1,144 \mathrm{~J} / \mathrm{g}$ release of energy for a $6 \%$ by weight addition of $\mathrm{MB}_{10}$ additive. This value corresponds to the amount of heat that is released by the combustion of PMMA during the firing process. In fact, it is equal to the lower heating value of the PMMA sample (i.e., 23,291 J/g) weighted by its percentage of addition (i.e., $6 \%$ by weight) in the clay ceramic. This means that the entire amount of energy from PMMA is released during the firing process. The $\mathrm{MB}_{50}$ additive has a same pure organic nature as the $\mathrm{MB}_{10}$ additive. Hence, the $6 \%$ by weight addition of $\mathrm{MB}_{50}$ additive induces a same release of $1,160 \mathrm{~J} / \mathrm{g}$. The amount of energy released during the firing process is then related to the percentage of organic additive along with their organic fraction.

The firing process of the clay ceramic involves $1,550 \mathrm{~J} / \mathrm{g}$ of energy. This value corresponds to the amount of energy required to reach the firing temperature of $950^{\circ} \mathrm{C}$, in addition to the amount of energy absorbed by the clay transformations. The increase of the temperature from 30 to $950^{\circ} \mathrm{C}$ requires $920 \mathrm{~J} / \mathrm{g}$ of energy. On the other hand, $630 \mathrm{~J} / \mathrm{g}$ of energy is absorbed by the dehydration, dehydroxylation, and decarbonation reactions at temperatures up to $950^{\circ} \mathrm{C}$. The combustion of $\mathrm{MB}_{10}$ and $\mathrm{MB}_{50}$ additives does not induce any modification of the clay transformations. Therefore, the firing process of the clay ceramic with organic additives also requires $1,550 \mathrm{~J} / \mathrm{g}$ of energy.

The amount of energy released by the combustion of $\mathrm{MB}_{10}$ additive covers $73.8 \%$ of the amount of energy required by the firing process. The $\mathrm{MB}_{50}$ additive provides a same energetic contribution of $74.8 \%$. Therefore, the particle size of the organic additives has no apparent effect on the energetic contribution. The energetic contribution is related to the percentage of organic additive with their organic fraction. A greater addition of such pure organic additives could cover the entire amount of energy required by the firing process. This means that the use of small organic additives as poreforming agents in clay ceramics can provide both an improvement of the thermal/mechanical properties and extensive energy savings.

\section{Implications}

The implications of this research are significant in the field of building materials. The building materials, such as fired clay bricks, are

Table 3. Energy Balance of the Clay Ceramic with a $6 \%$ by Weight Addition of $\mathrm{MB}_{50}$ and $\mathrm{MB}_{10}$ Additives

\begin{tabular}{lccc}
\hline Samples & $\begin{array}{c}\text { Energy } \\
\text { released } \\
(\mathrm{J} / \mathrm{g})\end{array}$ & $\begin{array}{c}\text { Energy } \\
\text { required } \\
(\mathrm{J} / \mathrm{g})\end{array}$ & $\begin{array}{c}\text { Contribution } \\
(\%)\end{array}$ \\
\hline Clay $+6 \%$ by weight $\mathrm{MB}_{10}$ & 1,144 & 1,550 & 73.8 \\
Clay $+6 \%$ by weight $\mathrm{MB}_{50}$ & 1,160 & 1,550 & 74.8
\end{tabular}

used for their thermal and mechanical properties. The literature has shown an improvement of the thermal properties using organic wastes as pore-forming agents. The thermal conductivity of the fired clay bricks decreased by 18 (Aouba et al. 2016) up to $51 \%$ (Kadir and Mohajerani 2011) with a 5\% by weight addition of olive stone flour or cigarette butts. However, the improvement of the thermal properties was associated with a decrease in the mechanical properties. The compressive strength of the bricks with a $5 \%$ by weight addition of olive stone flour or cigarette butts decreased by 31 up to $80 \%$.

In this study, the thermal and mechanical properties of a clay ceramic used for building applications were improved at the same time using organic additives with a small particle size. The $6 \%$ by weight addition of small organic additives decreased the thermal conductivity by $11 \%$. This decrease in the thermal conductivity is slightly lower than that obtained in the literature (18-51\%). Nevertheless, it was associated with a $33 \%$ increase of the flexural strength. This improvement of the mechanical properties is a step forward compared with the different losses that are observed in the literature (30-80\%). In fact, it suggests that the thermal and mechanical properties of fired clay bricks can be improved by the addition of many organic wastes using a preliminary reduction of their particle size.

The amount of energy that was released by the combustion of the organic additives also covered $73.8 \%$ of the amount of energy required by the firing. Therefore, the use of small organic additives as pore-forming agents provides an improvement of the performances as well as energy savings in the clay bricks industry. This reduces greenhouse gases emissions and contributes toward the objectives of reducing the impact of building materials on the global environment.

\section{Conclusions}

This research investigated the impact of the particle size distribution of organic additives on the microstructure of a clay ceramic and its thermal and mechanical properties. The impact of the particle size distribution was elucidated by the addition of a thermoplastic polymer in one form of $10-\mu \mathrm{m}$ particles and one form of $50-\mu \mathrm{m}$ particles. In fact, the organic additives were subjected to combustion during firing of the clay ceramic. The combustion occurred on a free range of temperatures between 250 and $450^{\circ} \mathrm{C}$. The reactions of the clay were then not modified by the combustion of the organic additives.

The transformation of the organic additives into water and carbon dioxide resulted in a porosity formation. The porosity was conserved during the firing process up to $950^{\circ} \mathrm{C}$. Moreover, the pore size diameter of the clay ceramic corresponded to the particle size distribution of the organic additives. The impact of the organic additives on the thermal and mechanical properties of the clay ceramic was then conserved in the form of porosity after firing.

The 10- and $50-\mu \mathrm{m}$ pores resulting from the combustion of the organic additives induced a same decrease in the thermal conductivity. In fact, the thermal conductivity depended on the percentage of porosity. The thermal conductivity was then controlled by the percentage of organic additives along with their organic fraction. However, the $10-\mu \mathrm{m}$ pores induced a greater increase of the Young's modulus and of the flexural strength than the $50-\mu \mathrm{m}$ pores. In fact, the Young's modulus and the flexural strength depended on the percentage of porosity as well as the pore size diameter. The mechanical properties were then controlled by the percentage of organic additives along with their organic fraction and their particle size. 


\section{Acknowledgments}

The authors would like to acknowledge the TERREAL Company for financial support and scientific contribution to this study. We also thank the staff of the ICA and RAPSODEE Research Centers at Ecole des Mines d'Albi for its assistance with the research.

\section{References}

Andreola, F., Barbieri, L., Corradi, A., Lancellotti, I., and Manfredini, T. (2001). "The possibility to recycle solid residues of the municipal waste incineration into a ceramic tile body." J. Mater. Sci., 36(20), 4869-4873.

Aouba, L., Bories, C., Coutand, M., Perrin, B., and Lemercier, H. (2016). "Properties of fired clay bricks with incorporated biomasses: Cases of olive stone flour and wheat straw residues." Constr. Build. Mater., 102(1), 7-13.

ASTM International. (2010). "Standard test methods for flexural properties of unreinforced and reinforced plastics and electrical insulating materials." ASTM D790-10, West Conshohocken, PA.

Baillez, S., and Nzihou, A. (2004). "The kinetics of surface area reduction during isothermal sintering of hydroxyapatite adsorbent." Chem. Eng. J., 98(1-2), 141-152.

Bánhidi, V., and Gömze, L. A. (2008). "Improvement of insulation properties of conventional brick products." Mater. Sci. Forum, 589, 1-6.

Bories, C., Aouba, L., Vedrenne, E., and Vilarem, G. (2015). "Fired clay bricks using agricultural biomass wastes: Study and characterization." Constr. Build. Mater., 91, 158-163.

Bories, C., Borredon, M. E., Vedrenne, E., and Vilarem, G. (2014). "Development of eco-friendly porous fired clay bricks using poreforming agents: A review." J. Environ. Manage., 143, 186-196.

Demir, I. (2008). "Effect of organic residues addition on the technological properties of clay bricks." Waste Manage., 28(3), 622-627.

Dondi, I., Mazzanti, F., Principi, P., Raimondo, M., and Zanarini, G. (2004). "Thermal conductivity of clay bricks." J. Mater. Civ. Eng., 10.1061 /(ASCE)0899-1561(2004)16:1(8), 8-14.

Ducman, V., and Kopar, T. (2001). "Sawdust and papermaking sludge as pore-forming agents for lightweight clay bricks." Ind. Ceram., 21(2), 81-86.

Eliche-Quesada, D., Martínez-Martínez, S., Pérez-Villarejo, L., IglesiasGodino, F. J., Martínez-García, C., and Corpas-Iglesias, F. A. (2012). "Valorization of biodiesel production residues in making porous clay brick.” Fuel Process. Technol., 103, 166-173.
Kadir, A. A., and Mohajerani, A. (2011). "Recycling cigarette butts in lightweight fired clay bricks." Constr. Mater., 164(5), 219-229.

Korah, L. V., Nigay, P. M., Cutard, T., Nzihou, A., and Thomas, S. (2016). "The impact of the particle shape of organic additives on the anisotropy of a clay ceramic and its thermal and mechanical properties." Constr. Build. Mater., 125, 654-660.

Mendívil, M. A., Muñoz, P., Morales, M. P., Letelier, V., and Juárez, M. C. (2017). "Grapevine shoots for improving thermal properties of structural fired clay bricks: New method of agricultural-waste valorization." J. Mater. Civ. Eng., 10.1061/(ASCE)MT.1943-5533.0001892, 04017074.

Mohajerani, A., Kadir, A. A., and Larobina, L. (2016). "A practical proposal for solving the world's cigarette butt problem: Recycling in fired clay bricks.” Waste Manage., 52, 228-244.

Monteiro, S. N., Alexandre, J., Margem, J. I., Sánchez, R. J., and Vieira, C. M. F. (2008). "Incorporation of sludge from water treatment plant into red ceramic.” Constr. Build. Mater., 22(6), 1281-1287.

Monteiro, S. N., and Vieira, C. M. F. (2014). "On the production of fired clay bricks from waste materials: A critical update." Constr. Build. Mater., 68, 599-610.

Muñoz Velasco, P., Ortiz, M. P., Giró, M. A., Melia, D. M., and Rehbein, J. H. (2015). "Development of sustainable fired clay bricks by adding kindling from vine shoot: Study of thermal and mechanical properties." Appl. Clay Sci., 107, 156-164.

Nigay, P. M., Cutard, T., and Nzihou, A. (2017). "The impact of heat treatment on the microstructure of a clay ceramic and its thermal and mechanical properties." Ceram. Int., 43(2), 1747-1754.

Phonphuak, N., and Chindaprasirt, P. (2014). "Types of waste, properties, and durability of pore-forming waste-based fired masonry bricks." Ecoefficient masonry bricks and blocks: Design, properties and durability, F. Pacheco-Torgal, P. B. Lourenço, J. A. Labrincha, P. Chindaprasirt, and S. Kumar, eds., Woodhead Publishing, Cambridge, U.K., $103-127$.

Tarvornpanich, T., Souza, G. P., and Lee, W. E. (2008). "Microstructural evolution in clay-based ceramics. II: Ternary and quaternary mixtures of clay, flux, and quartz filler." J. Am. Ceram. Soc., 91(7), 2272-2280.

Ukwatta, A., and Mohajerani, A. (2017). "Effect of organic content in biosolids on the properties of fired-clay bricks incorporated with biosolids.” J. Mater. Civ. Eng., 10.1061/(ASCE)MT.1943-5533.0001865, 04017047.

Zhang, L. (2013). "Production of bricks from waste materials-A review." Constr. Build. Mater., 47, 643-655. 